\title{
DISCURSO DA
}

\section{PROPAGANDA E}

DIRETRIZES

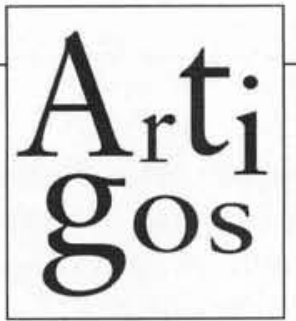

nacionais

\section{CURRICULARES ${ }^{1}$}

\section{Diretrizes Curriculares introduzem mudanças que permitem ao professor trabalhar interdisciplinarmente os discursos do cotidiano, tais como os da publicidade}

A Lei 9.394, de 20 de dezembro de 1996, que estabelece as diretrizes e bases da educação nacional, enuncia em seu Art. $1^{\circ}$ : "A educação abrange os processos formáticos que se desenvolvem na vida familiar, na convivência humana, no trabalho, nas instituições de ensino e pesquisa, nos movimentos sociais e organizações da sociedade civil e nas manifestações culturais".

Ressalta-se assim que, apesar de essa Lei disciplinar a educação escolar, a educação não se restringe apenas à escola. Isso torna importante refletir, principalmente, sobre o papel dos meios de comunicação na vida das pessoas e de que modo eles podem contribuir ou não para o exercício da cidadania.

As Diretrizes Curriculares Nacionais para o Ensino Médio (DCNEM), por sua vez, estabelecem um conjunto de definições doutrinárias sobre princípios, fundamentos e procedimentos a serem observados na organização pedagógica e curricular, centrando-se, assim, nos princípios pedagógicos da identidade, diversidade e autonomia, da interdisciplinaridade e da contextualização, adotados como estruturadores dos currículos do ensino médio. Ou seja, todas as ações pedagógicas da escola deverão ser coerentes com esses princípios.

Entre tantos princípios, fundamentos e procedimentos das DCNEM, é de suma importância destacar que a preocupação não é meramente conteudística, estando voltada principalmente para o fortalecimento da solidariedade, da tolerância, da formação de valores, da formação ética, do exercício da cidadania. A interdisciplinaridade e a contextualização, princípios pedagógicos estruturadores do currículo, permitem perceber claramente que as habilidades e competências estão em primeiro plano, isto é, vincular a educação ao mundo do trabalho e à prática social, ser crítico e ter autonomia intelectual, ser capaz de continuar aprendendo, ter

\section{A AUTORA}

Cláudia Lukianchuki

Doutoranda na ECA/USP e professora do Centro

Federal de Educação Tecnológica (Cefet-SP). 
flexibilidade para adaptar-se às novas condições de ocupação, compreender os fundamentos científicos e tecnológicos, relacionar a teoria com a prática.

Tudo novo? Nada novo. Entretanto, algo há a salientar: reforça-se uma educação que não estimule a simples memorização e, ainda menos, o estudo apenas para fazer provas e passar de ano. As restrições, assim, não dizem respeito ao que estabelecem os conteúdos das Diretrizes Curriculares Nacionais, mas às políticas de implantação (ou à falta delas). Ou seja, esta é mais uma reforma de ensino sem uma política eficaz de implantação, que ofereça aos estabelecimentos de ensino condições de capacitar os seus docentes/ profissionais de educação.

Embora, para conceber e elaborar o seu projeto pedagógico nesta reforma do ensino em nível nacional, o destaque seja o fortalecimento da autonomia das escolas, como pôr em prática de fato essa autonomia? É preciso um trabalho coletivo, ou seja, que todos os professores/profissionais da educação participem da elaboração do projeto pedagógico da escola e o ponham em prática. Caso contrário, repete-se a fórmula tão comum: faz-se um belo projeto pedagógico que, como se diz no linguajar cotidiano, fica na gaveta.

Autonomia, portanto, só é possível quando são oferecidas condições para que ela se efetive, ou seja, os profissionais terão de ter boa formação, estar atualizados/ capacitados para um projeto pedagógico coerente com a LDB, com as DCNEM. Autonomia sem infra-estrutura e sem capacitação é o mesmo que nada. Essas diretrizes não podem ser utopias, algo distante da realidade. Mas parece que infelizmente caminham para isso.

\section{TRÊS PRINCÍPIOS DAS DIRETRIZES}

Retomando, as DCNEM trazem três princípios: a estética da sensibilidade, a política da igualdade e a ética da identidade. Para um educador isso não é nada novo. O grande diferencial está na reafirmação dessas questões como um sinal de alerta em relação aos grandes problemas que o mundo contemporâneo nos coloca.

Tão importante quanto conhecer os conteúdos de Química, Física, História etc. é reforçar os valores afetivos e a tolerância entre as pessoas (atitude essa de que estamos carentes). Por isso, não à escola reprodutiva! Sim à escola que estimula a criatividade, a inventividade, a criticidade.

Mas como o professor irá impregnar seu aluno de estética da sensibilidade (contra a repetição e a padronização, com estímulo à criatividade e à inventividade, à curiosidade para o inusitado, à afetividade, à convivência com a diversidade, à valorização da qualidade etc.) se ele próprio não foi preparado para isso? Só é capaz de fazê-lo bem quem se capacitou, quem está preparado para enfrentar as incertezas e a imprevisibilidade, quem sabe conviver com a diversidade, enfim, quem, ao longo de sua vida, vem tentando no cotidiano, inclusive, melhorar sua condição de vida e das pessoas.

Não há disciplina alguma que dê conta de explicar tudo. Por isso é necessária a relação interdisciplinar, pela qual o conhecimento de algo seja explicitado por várias áreas de conhecimento, possibilitando, assim, uma visão mais completa do assunto. Não se aceita, portanto, a idéia de uma disciplina ser mais importante do que outra. Todas contribuem mais ou menos intensamente para a explicação de um fato/assunto. A idéia de que a interdisciplinaridade subtrai a especificidade de cada disciplina não tem fundamento. Quem assume uma atitude interdisciplinar conhece profundamente a sua disciplina. Sua aula é feita 
por várias mãos, sem ser um amontoado de conhecimentos desvinculados. A interdisciplinaridade pode ser metaforicamente comparada a uma orquestra, que possui vários instrumentos musicais, cada qual com sua especificidade, mas que, no conjunto, mostra um resultado diferente daquele que conseguiria individualmente.

Quanto ao princípio da política da igualdade, não traz nada de novo: todo educador sério luta e lutará pelo reconhecimento desse direito, que, na realidade, ainda revela a enorme defasagem entre o que se fala e o que se faz, entre a teoria e a prática. A discriminação ainda persiste, nas suas mais variadas formas, nas sociedades, em todo o mundo e nãoé muito diferente aqui no Brasil. O professor deverá ter sempre isso em mente, não ser preconceituoso, o que implica, mais uma vez, profundos conhecimentos sobre o que está acontecendo não só no mundo como destacadamente no Brasil. Mascarando a realidade não se atinge a tão propalada igualdade.

À política da igualdade acrescenta-se um outro princípio igualmente importante: a ética da identidade. Nada mais estarrecedor do que discutir esse princípio em um país que insiste em se manter colonizado culturalmente, descontadas as exceções. A identidade nacional fica fortemente comprometida ao se valorizar mais o que é estrangeiro em detrimento do nacional. Em um mundo globalizado, essa questão não deveria provocar surpresa, mas convém ressaltar que não estamos falando de anulação de um pelo outro, e sim da presença de um em outro. Outra forma de identidade, que é preciso resgatar urgentemente, é com a própria escola. Dificilmente temos hoje exemplo desse tipo de identidade. Basta ver a depredação que está acontecendo nas e com as escolas, especialmente as da rede pública, fruto da crise social que estamos vivendo, da crise de valores que assola o país, mas também de uma desatenção à idéia de que a escola é um espaço público por excelência. Por conseguinte, o aluno não deve só passar por ela, mas ajudar a construí-la, aprendendo assim a valorizá-la e se identificando com ela.

Como o professor poderá traduzir essa questão na sala de aula? Através de uma aula dialogada, que valorize o conhecimento que $o$ aluno já tem, busque ressaltar a experiência pessoal de cada um, na medida do possível mostre que ele também é muito importante, não só falando, mas também fazendo. Uma aula em que não se coloque o tema na lousa e já se comece a falar do assunto. Na aula em que se constrói conjuntamente, o professor não é o centro das atenções, o dono único e exclusivo do conhecimento, embora, pela vivência/conhecimento, ele tenha mais domínio. É necessário, antes de mais nada, extrair do aluno o conhecimento que ele tem sobre o assunto e desenvolver a aula conjuntamente. Assim, o aluno se sentirá valorizado e dará, com certeza, muitas contribuições, e o professor constatará que sempre se está aprendendo.

Todas as ações pedagógicas da escola, inclusive as aulas, devem estar imbuídas dos princípios contidos nas DCNEM, mas também para isso é preciso que os professores sejam capacitados.

Outra referência importante nas DCNEM são os saberes das três áreas curriculares: Linguagens e Códigos, Ciências da Natureza, Matemática e Ciências Humanas, e suas respectivas tecnologias.

\section{CONTEÚDOS PROGRAMÁTICOS}

As áreas, reunidas assim, revelam uma preocupação interdisciplinar que poderá levar até à transdisciplinaridade, talvez uma etapa a 
ser atingida no futuro. Essa nova concepção de áreas tende, obviamente, a provocar mudanças, inicialmente pequenas, mas que devem ser paulatinas até a sua concretização final, se se pretende aplicar os princípios contidos nas DCNEM. Dessa forma, o horário de aulas deve ser pensado de maneira pedagógica para facilitar o trânsito entre as disciplinas; devem-se definir os conteúdos não só disciplinarmente mas também interdisciplinarmente, uma vez que as DCNEM não definem os conteúdos programáticos (aqui um alerta: se não se deve cumprir um ano letivo com o objetivo único de dar tudo o que se programou a qualquer custo, também não se deve deixar de definir os conteúdos programáticos prioritários).

Uma dúvida permanece: ou todos os conteúdos programáticos continuarão os mesmos em todas as escolas, seguindo a velha regra, ou cada escola elegerá o seu conteúdo, em cada disciplina, e não haverá unidade alguma entre as escolas, o que também é um erro. Como fica então a base nacional? A dúvida permanece. Estabelecer a unidade, a base nacional, eleger os conteúdos tomando como referência as competências descritas nas DCNEM não tem sido nada fácil, uma vez que nem todos dominam os conceitos de competências e habilidades, identificando, para cada uma delas, as bases tecnológicas, as bases científicas e as bases instrumentais. Se está sendo difícil incorporar os conceitos, a prática deles em sala de aula continua nula ou quase nula.

Posto isso, vamos deter-nos, mais especificamente, na área de Linguagens e Códigos, que é nosso campo de atuação. De imediato, vê-se nitidamente que, apesar de cada disciplina (Português, Educação Artística, Educação Física, Inglês, Informática) conservar a sua especificidade, elas devem relacionar-se entre si ou, de acordo com as DCNEM:

- compreender e usar os sistemas simbólicos das diferentes linguagens como meios de organização cognitiva da realidade pela constituição de significados, expressão, comunicação e informação;

- confrontar opiniões e pontos de vista sobre as diferentes linguagens e suas manifestações específicas;

- analisar, interpretar e aplicar os recursos expressivos das linguagens, relacionando textos com seus contextos, mediante a natureza, função, organização, estrutura das manifestações, de acordo com as condições de produção e recepção.

É importante discutir como inserir adequadamente os meios de comunicação na sala de aula sem que estes ocupem o espaço que é próprio da escola, substituindo-o. É bastante discutível que os meios de comunicação exerçam uma função pedagógica. Pode-se dizer até que não é essa a sua função. Mas será que a educação, em seu sentido mais amplo, não é papel de todos, independentemente de se estar em situação escolar? Se acharmos o contrário, é bom repensar o Art. $1 .^{\circ}$ da LDB/96, referido no início.

Portanto a televisão, o rádio, o jornal não serão levados para a sala de aula como espécies de livros didáticos, o que seria um absurdo e com o que estaríamos invertendo os papéis. Contudo, eles devem estar presentes na sala de aula, objetivando com isso, principalmente, fazer uma leitura crítica desses meios que, sem dúvida alguma, fazem parte do nosso cotidiano.

Se eles estão impregnados em nossas vidas, é imprescindível conhecê-los. É inegável o papel dos meios de comunicação na formação de uma nova visão e no desenvolvimento de uma nova sensibilidade, sem entrar no mérito, agora, se é boa ou ruim. Afinal, não se 
deve esquecer de que o processo educativo, em síntese, é a construção da consciência crítica.

\section{PODER DA PALAVRA ${ }^{2}$}

Não é possível pensar a comunicação sem pensar nos estudos de linguagem. Destacaremos mais particularmente, aqui, a linguagem verbal, sem que com isso queiramos mostrar ser ela mais importante do que as outras. Mesmo porque não é essa a nossa visão. Contudo não podemos nos esquecer de que "só o código lingüístico, a palavra, possui a condição de penetrar todos os campos, de se fazer presente em todos os domínios, de interpretálos, inter-relacionando-os e facultando, portanto, as mudanças" ${ }^{3}$.

Não partilhamos da visão de comunicação apenas como transmissão de conhecimentos. Ela é muito mais do que isso: comunicar-se é participar de um contínuo processo de elaboração do real vivido, ou seja, a comunicação se dá, necessariamente, nas inter-relações enunciador/enunciatário ${ }^{4}$ ambos (re)construindo o cotidiano, os valores da sociedade em que vivem, cujo resultado aparece manifesto na elaboração e leitura do produto cultural.

O professor de Português deverá, portanto estar antenado e ansiar por atualizar o ensino de Língua Portuguesa de modo a integrar o cotidiano e o que se aprende em sala de aula.

Partimos do pressuposto de que um bom desempenho lingüístico se verifica quan- do o aluno tem aptidão para ler e produzir textos de forma eficiente. Preocupação essa que alia o conhecimento da língua à formação do indivíduo crítico, consciente, participante do processo de transformação social. Mais do que a língua dada, importa a palavra dando-se. Por essa razão, a linguagem verbal não é apenas instrumento, mas está intimamente associada ao pensamento, mais precisamente ao pensamento verbal ${ }^{5}$. O papel ativo da linguagem no pensamento é claro: o sistema lingüístico é o suporte do pensamento conceptual e a linguagem, enquanto produto definido, constitui o fundamento social do pensamento individual. A linguagem humana é uma capacidade inata, mas a palavra não; esta só se desenvolve socialmente.

É nosso objetivo mostrar que o mundo é efeito da linguagem e que a linguagem verbal influencia nosso modo de percepção da realidade. Entendemos essa afirmação na perspectiva de Bakhtin ${ }^{6}$, de que todo signo lingüístico reflete/refrata a realidade. E mais, todo texto tem uma intencionalidade e é preciso conhecer os mecanismos que a sustentam.

Importa, assim, verificar que, além do poder econômico, existe um outro tão igualmente avassalador: o poder das palavras. Desenvolver e enriquecer a linguagem é ser capaz não só de compreender o mundo, agir sobre ele, mas, principalmente, de autoconstruir-se.

2. As reflexões sobre o ensino de Língua Portuguesa e a sua aplicação em sala de aula são exemplos extraídos da nossa experiência/ vivência como docente do Centro Federal de Educação Tecnológica (CEFET-SP).

3. BACCEGA, Maria Aparecida. Comunicação e linguagem. São Paulo: Moderna, 1998. p. 22.

4. Enunciador/enunciatário são conceitos que se complementam ao significarem: enunciador o indivíduo/sujeito que, após reelaborar os discursos que recebe, constrói o seu próprio; e enunciatário o indivíduo /sujeito que recebe os discursos e, para compreendê-los, vai apropriar-se deles a partir de sua realidade, de seu grupo/classe social. Portanto, em todo o enunciatário há também um enunciador. Ver mais sobre o tema em: BACCEGA, Maria Aparecida. Palavra e discurso. História e literatura. São Paulo: Ática, 1995. (N. Ed.) 5. A relação linguagem-pensamento de que falamos compreende as idéias de: SCHAFF, Adam. Linguagem e conhecimento. Coimbra: Almedina, 1974. e VYGOTSKY, L.S. Pensamento e linguagem. São Paulo: Martins Fontes, 1989.

6. BAKHTIN, M. (Voloshinov). Marxismo e filosofia da linguagem. São Paulo: Hucitec, 1979. 
É a linguagem que possibilita ao indivíduo poder avaliar criticamente o mundo que lhe é passado, manifestar-se interagindo e possibilitar as marcas dessa transformação.

Desconhecendo os mecanismos da linguagem, dificilmente se terá consciência da exploração/manipulação a que se é submetido diariamente. Só a intuição não é suficiente. É preciso conhecimento. Assim, a função do comunicador, que somos todos, não é a de reproduzir o que se veiculou, mas sim a de reelaborar a informação passada, saindo da passividade e assumindo o ser pensante que é. Dialogando com o outro, desvela-se a sua intenção. As significações são plurivalentes. $\mathrm{O}$ desafio está em percebê-las.

$A$ vida se formula em textos. E o estudo dos mecanismos da linguagem é a maneira de se chegar a eles. E mais: pode-se, através da linguagem, construir/desconstruir todo um universo. Para isso, é preciso ser aguçado leitor dos textos que estão na vida, assumir integralmente a condição de cidadão no exercício pleno de seus direitos e deveres. A cidadania requer preparação. Afinal, o outro não é alguém tão distante de você. A subjetividade de cada um se constitui a partir da realidade social, que compreende um determinado momento histórico, social, cultural e econômico. O que equivale a dizer que o discurso de um indivíduo se forma no bojo dos vários discursos sociais. Logo, o outro não é tão diferente assim, o seu interesse é que poderá sê-lo. Como nos falam Bakhtin e Ducrot em suas obras, entre outros, não há unicidade do sujeito, seu discurso é o discurso de várias vozes - a polifonia. Isto é, o eu individual é social.

\section{GRAMÁTICA TEXTUAL DA PUBLICIDADE?}

Os objetivos básicos do estudo da gramática textual podem ser assim enunciados:

- entender que a linguagem verbal é mediadora entre o homem e a realidade;

- apreender o verbal no conjunto dos discursos e textos existentes na sociedade e conduzir à reflexão das questões de poder das relações sociais, das formações ideológicas, enfim, da comunicação verbal;

- pensar dialeticamente a realidade social, contribuindo para que se perceba que o emissor não só reflete mas também refrata a realidade, capacitando-o a trabalhar com as diversas modalidades de organização textual;

- perceber que o campo da comunicação se constrói na interação entre o pólo emissor e o pólo receptor.

Há várias razões para a escolha do texto publicitário. Uma delas é que o entendemos como (pré)determinador dos demais textos, principalmente os que são veiculados nos meios de comunicação de massa. Assim como os demais, ele está presente no nosso cotidiano e interferindo nas nossas vidas, alterando o nosso comportamento. Outra razão é a aparente contradição que esse texto revela: de um lado, um ar de leveza, de descontração, veiculando idéias como se fossem momentos de lazer, de diversão; de outro, uma intencionalidade muito bem construída como texto. Em outras palavras, é a "fábrica de ilusões e de frustrações" simultaneamente. Gratifica e pune, conforme Jean Baudrillard ${ }^{8}$.

Assim, entender o texto publicitário é percorrer caminhos adversos, até mesmo pa-

7. Neste texto compreende-se por gramática textual as diferentes estratégias de uso da língua para a estruturação da linguagem publicitária. (N. Ed.)

8. BAUDRILLARD, Jean. Significação da publicidade. In: LIMA, Luís Costa (org.). Teoria da cultura de massa. Rio de Janeiro: Paz e Terra, 1983. p. 273-285. O autor explica que "A sociedade adapta-se totalmente a você, integre-se totalmente nela". É claro que a reciprocidade é falsificada: é uma instância imaginária que se adapta a você, enquanto que, em troca, você se adapta a uma ordem bem real. 
radoxais. Não se pretende discutir de quem é a culpa, mas sim evidenciar idéias sobre o assunto e também posicionar, em certos aspectos, na relação enunciador/enunciatário, o enunciatário que, nesse jogo de $e u$ e outro, tem um papel discutível e pode ser tanto vítima como sujeito, ou nem uma coisa nem outra. Há previsões, certezas, meias certezas. E há dúvidas. Caminhos esses que são perseguidos quando se estuda esse tipo de texto.

É importante ressaltar que a publicidade é uma forma de comunicação persuasiva. E hoje podemos dizer que, muito mais que vender o produto, ela dita modelos, estilos de vida.

Aí é que começam a surgir as grandes questões. Ou seja, a discriminação, a segregação que é um ponto forte nesse tipo de texto. Se você não usa o produto $\mathrm{X}$, não pertence ao grupo, está fora, descartado. Ressalte-se o efeito que isso provoca no jovem, principalmente. Mas é também igualmente importante o que provoca nas pessoas em geral.

Se é importante lembrar o papel da publicidade, igualmente o é dizer que ela não inventou isso. Isso significa que a publicidade nada mais faz do que refletir o modo de pensar do capitalismo. Ela não cria, mas reflete o que está na sociedade. O que se pode afirmar, com certeza, é que ela reforça esses valores, isso sim. Valores perenes, como a juventude e a beleza, estar na moda; a elegância, a sofisticação; a idéia de sucesso pessoal ligado à posse de bens, ao uso de determinada roupa ou carro, à bebida que se toma etc.; a sedução é figurativizada pelas roupas íntimas femininas, por batons de tons vermelhos, sensuais. "Enfim, requinte, classe, elegância, sucesso, sta- tus, alto padrão de vida são apregoados [...] são alcançados se consumirmos tais e tais produtos"

$\mathrm{O}$ perigo está na expectativa que se cria no indivíduo não como algo saudável, mas sim mexendo com os seus desejos. E é ainda Baudrillard quem nos alerta: "Nenhum desejo subsiste sem a mediação de um imaginário coletivo" ${ }^{10}$. Se todos querem, eu também quero: as necessidades individuais são controladas através do funcionamento do coletivo. Os produtos (a maioria deles) não são democráticos, não estão ao alcance de todos. Então, busca-se sempre incutir nas pessoas aquilo que gostariam de ser, e não o que são. Ficção se transforma em realidade, ainda que inconscientemente.

Mais que isso, há publicidade enganosa (ou mais enganosa): "Um brinde à qualidade de vida" (Brahma); "Liberdade é uma calça velha, azul e desbotada" (Jeans); "Se você é famoso, usa sandálias Havaianas".

Há os preconceitos ou formas estereotipadas como no caso de publicidade de eletrodomésticos, que são apresentados quase sempre por uma mãe. Ou os preconceitos em relação à mulher (a mulher é que deve servir, relação mais de permanência dos valores sociais do que de mudanças): "Receita/Ingredientes:/dois ovos/sal/JB/gelo/Modo de fazer:/Antes dele chegar, tire o gelo,/arrume os copos,/abra o JB/ Quando ele chegar, sirva o JB".

Há a manipulação dos valores ou ideais humanos: "A questão não é se você gosta ou não gosta de cigarro. (Sobre um fundo preto) / A questão é se você gosta ou não de liberdade". "Pode ser que fumantes e não-fumantes não concordem a respeito de cigarro, mas certamente concordam a respeito de liberdade."

Vistas as coisas por esse ângulo, a cobrança estende-se dos criadores da publicidade aos que participam dela, seja como ator ou como telespec- 
tador/leitor/ouvinte. A atriz Sônia Braga se recusa a fazer comerciais de produtos como cigarros, bebidas e projetos imobiliários ou carros destinados para a classe média alta. Ela afirma que não faz comerciais de produtos que prejudicam a saúde física ou emocional das pessoas. Acrescentando, ainda, que não gosta de fazer anúncios de imóveis e carros porque esses produtos não estão ao alcance de todos. Claro é que, em uma sociedade capitalista, é muito difícil não sucumbir ao dinheiro. Mas, como mostra a atriz, é possível. O papel social está nas mãos de cada um: educador, comunicador profissional ou não, leitor/telespectador.

\section{PUBLICIDADE REVELA VALORES DOMINANTES}

Em um paralelo entre um dos primeiros classificados sobre escravos (1809) e anúncios atuais, podemos notar em ambos, apesar da distância no tempo, que as pessoas são vistas ou se consideram como animais-objetos-mercadorias, transparecendo uma certa normalidade nessas relações. É a força determinista de uma sociedade com raízes escravocratas e que, portanto, produz relações de escravidão: o senhor e o escravo presentes nas relações afetivas, nas relações de trabalho, nas relações sociais. E a comunicação de tudo isso tanto pode reforçar esses valores como transformá-los. A comunicação não é um processo passivo.

"Em vinte de agosto do ano próximo passado, fugiu um escravo preto, por nome de Mateus, com os sinais seguintes: rosto grande e redondo, com dois talhos, um por cima da sobrancelha esquerda e outro nas costas; olhos pequenos, estatura ordinária; mãos grandes, dedos grossos e curtos, pés grandes e corpo grosso. $\mathrm{Na}$ loja de fazenda de Antônio José Mendes Salgado de Azevedo Guimarães, na rua da Quitanda n. 64 , receberá quem o entregar, além das despesas que tiver feito, $132 \$ 800$ de alvíssaras." "।

Sem nos estendermos na análise, que não é o objetivo neste momento, é possível imediatamente verificar os valores que estão sendo comunicados: o que se evidencia bem claramente é o ser humano como mercadoria - são os determinismos culturais da época. Não é possível desconsiderar, portanto, a época em que foi elaborado o texto, suas condições de produção.

"Perdeu-se uma esposa. Quem encontrar devolva para o Lima. Ela tem olhos bem claros, estou desesperado. Ela atende pelo nome de Neca."(Folha de S. Paulo, 14/02/92)

"Gata sexy, linda tipo MIGNON, morena olh. verdes, jovem de 34a., VIP, culta, sofisticada, indep. financ., divorciada, quer conhecer homens livres $36 / 46 \mathrm{a}$., alto $(1,80 \mathrm{~m}$ p/ cima), atraentes, de mesmo nível." CP 1214. (Folha de S.Paulo, 02/09/94.)

O que se observa entre um e outros é que as semelhanças não são meramente estruturais, isto é, de forma de construção do texto. Há muito mais que isso: uma visão de mundo que parece perpetuar-se notadamente: a cultura de uma sociedade escravocrata, patriarcalista, dominadora, presente não só nas relações afetivas, mas também nas de trabalho, enfim nas relações sociais como um todo.

Um bom exercício para se evidenciar que a publicidade é a materialização da ideologia capitalista é aquele em que se faz uma antipublicidade ou uma paródia de uma publicidade. Usaremos como exemplo de como se desconstroem/ constroem significados um anúncio da Coca-Cola e um poema concretista de Décio Pignatari. 


\section{Propaganda da Coca-Cola}

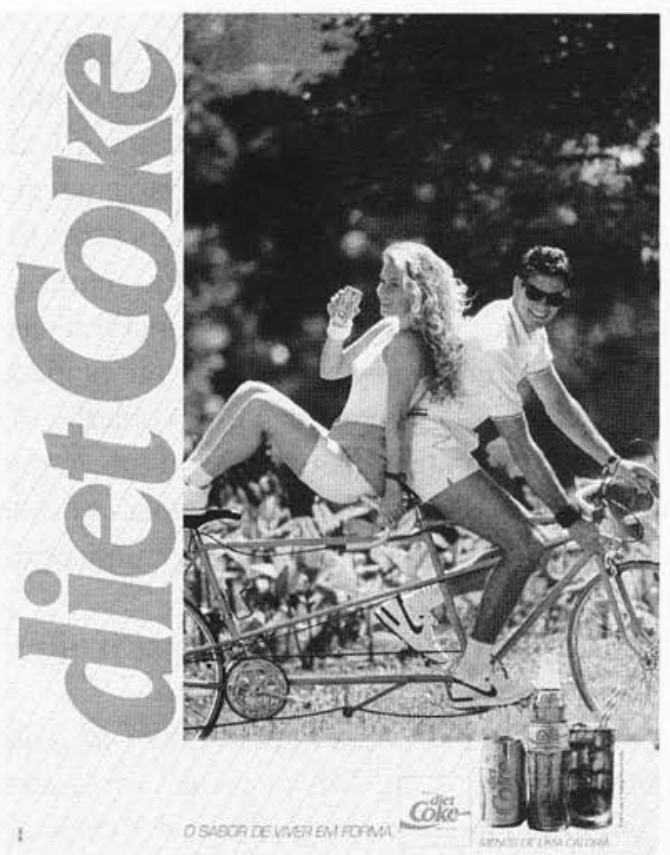

Caráter persuasivo da propaganda cria novas necessidades.

Em contraposição à publicidade da CocaCola, veja como o poema concretista abaixo desmonta o seu jogo persuasivo. Esse poema, é claro, não foi feito em relação a esta publicidade específica, mas às publicidades da Coca-Cola em geral.

beba coca cola
babe cola
beba coca
babe cola caco
caco
cola

cloaca

Publicidade ou antipublicidade? Ao usar recursos modernos, o poeta faz crítica ao consumo desenfreado, inclusive por ser um produto de multinacional. Também é alvo a forma persuasiva, extremamente insistente de divul- gar o produto. Para concretizar seu convite à congestão, Pignatari inicia o poema com a famosa frase do anúncio da Coca-Cola: Beba Coca-Cola, mas, a partir daí, vai decompondo as palavras em sílabas até chegar às letras ( c 1 o a c a ). A carga semântica explorada como recurso poético é inteiramente negativa: coca (droga); cola (o que gruda, o que causa dependência); babe (leva à idéia tanto de gostar do produto quanto da falta de controle, de alguém que perde a coordenação); caco (algo sem valor, porcaria); por isso tudo deve ir para a cloaca (fossa ou cano que recebe dejeções e imundícies), vocábulo único, que retoma todas as letras da palavra Coca-Cola. O consumo desenfreado é o excremento, que deve ser eliminado.

Para refletir: será que necessariamente a publicidade tem de ser enganosa? Não é possível produzir outro tipo de publicidade?

\section{Peça publicitária da Malboro}

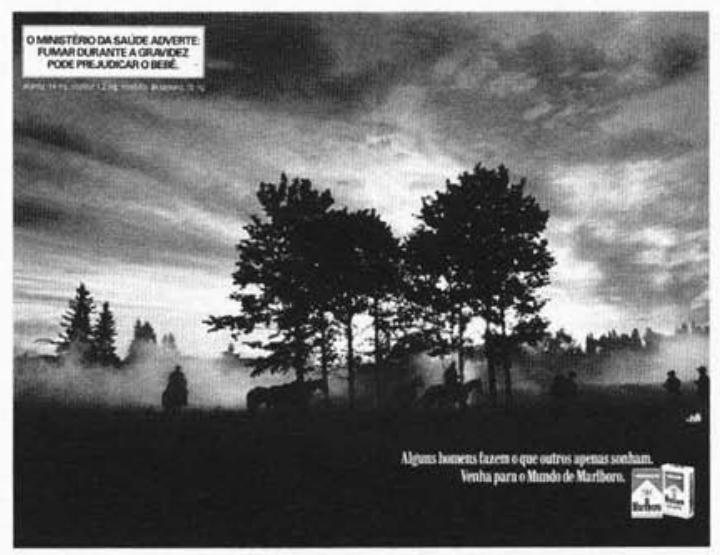

O cigarro, ao contrário do que afirma a publicidade, é responsável por doenças graves que levam à morte.

Convém lembrar, ainda, que a publicidade/propaganda não aparece só em textos específicos. Aparece, também, no corpo. Exemploé oque fazemos para chamar a atenção do outro, na relação afetiva ou social: vestimo-nos com um intui- 
to; nossas palavras, nossos gestos, tudo quer propagandear nossa imagem, para que consigamos atingir nosso intento. Recentemente apareceu a figura do urubu-publicitário. "O urubu-publicitárioé aquele gênero de propaganda especializado em pegar carona no luto da multidão. Basta morrer um ídolo popular e, portanto, lá está o urubu-publicitário. São homenagens feitas por mercadorias (como uma marca de cerveja, por exemplo, mas pode ser qualquer coisa) que sobrevoam o funeral. O urubu-publicitário não quer devorar nada do falecido, nada que não seja o amor que o povo tem por ele. Quer possuí-lo e depois transferi-lo para um produto qualquer"'2.

Isso não nos sugere fatos, relativamente recentes, do cenário político atual? As mortes do ministro Sérgio Motta e do deputado federal Luís Eduardo Magalhães. Retrato: primeiro morre um, depois, o outro; abalo nas negociações políticas; rosto triste do presidente, emocionado; ACM aparece na televisão chorando e, junto com FHC, pede, em homenagem a eles, que aprovem a reforma previdenciária em benefício do povo; choro e antropofagia.

\section{CARACTERÍSTICAS DO TEXTO PUBLICITÁRIO}

Os textos de publicidade/propaganda têm determinadas características, marcas que nem sempre são só suas. $\mathrm{Na}$ análise da publicidade abaixo destacamos algumas dessas marcas, enfatizando assim a sua gramática e os mecanismos que a sustentam.

Assim poderíamos dizer que: "O texto publicitário nasce na conjunção de vários fatores, quer psicossociais, quer do uso daquele enorme conjunto de efeitos retóricos aos quais não faltam as figuras de linguagem, as técnicas argumentativas, os raciocínios" 13 .

Com relação às marcas estruturais do texto publicitário (o tecido do texto, a sua gramática), observam-se, num primeiro momento, alguns elementos: o slogan, a ilustração e o texto verbal; num segundo momento, mais específico, a linguagem do texto, com as suas marcas e todas as formas de desvios, intencionais ou não.

A seguir, analisaremos uma publicidade feita para a mídia impressa ${ }^{14}$ com o objetivo de explicitar, na prática, as questões teóricas que foram abordadas e, também, evidenciar se existe ou não uma função pedagógica da comunicação.

\section{A Toshiba faz tudo para realizar o que você espera amanhã}

Para as pessoas, o nascer de um novo dia não traz apenas o sol. Traz também a esperança de um futuro melhor. Esta também é a visão da Toshiba, que caminha sempre em direção ao futuro para transformar esperanças em realidade.

No Brasil e no mundo inteiro, a Toshiba se empenha no desenvolvimento e aplicação de novas tecnologias. Apoiada numa grande equipe de engenheiros e no investimento de milhões de dólares, a Toshiba vem criando e lançando produtos de alta qualidade nas mais diversas áreas, como equipamentos médicos, eletrodomésticos, energia, geradores, motores, semicondutores e equipamentos de automação de escritórios.

Mais de cem anos de conquistas tecnológicas e confiabilidade fazem da Toshiba hoje um dos maiores grupos do mundo.

E a presença dos seus produtos melhorando a vida de milhões de pessoas é o maior incentivo que ela tem para continuar trabalhando assim nos próximos cem anos.

Toshiba 
Este é um texto publicitário de uma marca, Toshiba, de equipamentos eletroeletrônicos, que busca chamar a atenção para a qualidade tecnológica, tentando convencer os leitores a serem futuros consumidores.

No primeiro momento, há uma certa dificuldade a ser observada: o texto é longo; existe o predomínio da função referencial da linguagem e, conseqüentemente, o vocabulário é mais denotativo em nível literal ou na estrutura superficial do texto. No entanto, há uma pura conotação: Toshiba é o futuro.

Já no título caracteriza-se um outro enunciador, através da personificação "A Toshiba faz", e o enunciador propriamente dito fica menos aparente, podendo agir mais decisivamente através da marca, que aparece como um imperativo (a função conativa ${ }^{15}$ está implícita), trazendo um slogan que pode ser simplificado da seguinte maneira: "A esperança de um futuro melhor está com Toshiba".

Percebe-se, então, um raciocínio silogístico (entimemático, isto é, truncado/incompleto) que direciona todo o texto:

- premissa maior: as pessoas "do futuro" compram Toshiba;

- premissa menor: você é (ou quer ser) uma pessoa do futuro;

- conclusão: você deve comprar Toshiba e seu futuro será melhor.

-Vêem-se duas realidades de forte pressão psicossocial:

- compra-se Toshiba para não ser excluído do grupo social, que é considerado vanguardista;

- o império tecnológico é evidente e simboliza o futuro, portanto quem se excluir estará fadado ao atraso.

É possível verificar que o enunciador conceptualiza alguns elementos de sua experiência, os quais quer transmitir e deseja que sejam assimilados: "Toshiba faz o futuro com avançada tecnologia".

Nesse sentido, podem ser levantados alguns pontos do universo referencial ao qual pertence o enunciador/enunciatário, os chamados lugares:

- a sociedade capitalista é consumista (idéia de descartável ou mesmo de quantidade);

- existe competição entre os consumidores;

- nesse tipo de sociedade, privilegia-se o novo, o mais avançado tecnologicamente;

- é preciso simplificar os problemas do cotidiano.

Outros elementos se derivam daí:

- Toshiba é o melhor;

- Toshiba caminha sempre em direção ao futuro;

- Toshiba se empenha no desenvolvimento e aplicação de novas tecnologias;

- Toshiba vem criando produtos de alta qualidade.

Por esse ponto de vista, há um elemento comparativo implícito que visa privilegiar a marca entre as outras: "Os produtos da Toshiba têm mais qualidade que os das outras marcas".

O recurso da repetição também se faz presente, com a finalidade, no caso, de fixar a marca, que fica em evidência, tornando-se um elemento insubstituível e agente de transformação na vida das pessoas. Toshiba traz a carga semântica de mais humano, criando, agindo, transformando; assim devem ser, também, as pessoas. Verifica-se aqui a interferência da intenção comunicativa do produtor do texto: a identificação. Sendo este produto mais humano, fica-nos a pergunta: todos podem comprá-lo?

$\mathrm{O}$ argumento básico, para mudar o comportamento do enunciatário, é a capacidade já comprovada mundialmente. Se todo mundo já aprova (caráter hiperbólico), você também vai aprovar - é o que está implícito e de forma 
imperativa. Há um forte índice testemunhal, embora implícito. Evidenciam-se as várias vozes: do enunciador/produto, das pessoas que usam esse produto e da grande equipe de engenheiros que atesta a qualidade de Toshiba.

O que se destaca, no texto todo, são os lugares de qualidade: empenho e aplicação de novas tecnologias, equipe de engenheiros competentes, mais de cem anos de conquistas etc.; embora o texto todo também assinale o lugar de quantidade: todas as pessoas do futuro têm Toshiba, portanto você também deve tê-lo.

Para que a marca seja incorporada à vida das pessoas, além dos argumentos acima, elementos retóricos são trabalhados:

- a repetição da palavra Toshiba;

- a enumeração: enumeram-se os produtos Toshiba nas mais diversas áreas;

- a prosopopéia: Toshiba adquire características humanas;

- a metonímia: a marca pelo produto - o que se impõe é a marca;

- hipérbole: o exagero para convencer mais facilmente.

Enfim, os recursos utilizados visam reforçar no enunciatário a mensagem que se quer passar e fazer com que ele passe a consumir o produto divulgado, ou seja, buscam a adesão.

\section{IDENTIFICAÇÃO DE SENTIDOS}

A opção, então, pela gramática textual, como se buscou confirmar neste trabalho com o texto publicitário, faz com que o aluno não só saiba ler o texto do outro (que de alguma forma é também seu) como ao mesmo tempo construa o seu texto - passo determinante para a efetivação da aprendizagem. Não se privilegiam aqui apenas fórmulas gramaticais nem a extração de palavras do texto para a sua classificação e análise, mas a maneira como o texto é tecido. E, para isso, é claro que não podemos abdicar da gramática tradicional nem nos restringirmos só a ela. A gramática é um caminho, não o único nem o primeiro. Ela é importante como elemento de construção e de identificação.

Para atingir tais objetivos, algumas estratégias devem ser utilizadas: conversa inicial sobre a noção de texto, com vários exemplos; estudo da gramática do texto publicitário (leitura e análise de vários textos publicitários, destacando as características desse tipo de texto); abordar alguns aspectos teóricos como elemento-síntese dos aspectos fundamentais desse tipo de texto; usar mecanismos de construção indispensáveis para o desenvolvimento da leitura e produção de textos e, finalmente, realizar atividades de criação.

Ler-produzir um texto é, portanto, reconstruí-lo no campo das relações que se instituem entre ele e o ser humano. É fazer dessa relação uma produção social a partir da qual se possa refletir/refratar o universo no qual está inserida. O enunciador/enunciatário, bem como o enunciatário/enunciador precisam apreender-se como participantes (sujeitos) da História, e não como um de seus objetos. A saída não é a exclusão de textos dos currículos escolares, mas sim a sua (des)construção para a compreensão do mundo em que vivemos, seus valores e ideologias. Ou, como diz Henri Lefèbvre em relação ao texto publicitário: "A publicidade ganha a importância de uma ideologia. É a ideologia da mercadoria. Ela substitui o que foi filosofia, moral, religião, estética. Vai longe o tempo em que os publicitários pretendiam condicionar os sujeitos consumidores pela repetição de um slogan. As mais sutis fórmulas publicitárias de hoje em dia ocultam uma concepção do mundo" 16 . 
Assim, conhecer os mecanismos da linguagem, os recursos vários e identificar sua argumentatividade inerente é preparar-se para montar e desmontar os jogos de linguagem, conhecendo-lhes as armas. E o verbal perpassa todos os discursos, revelando-os em sua interioridade.

Dessa forma, no texto tomado como exemplo, a linguagem verbal delineia o universo publicitário e os seus objetivos. Não é apenas um discurso para levar a comprar determinado produto; é reflexo da sociedade em que ele se manifesta. A crítica à publicidade revela a própria sociedade que se superficializa, se materializa, se torna descartável, se propõe um eu mínimo. Esvazia-se o ser na busca do ter. E essa busca é desejo que, uma vez não-

Resumo: A partir de uma análise da nova LDB e das DCNEM, a autora questiona a autonomia proposta pela legislação, considerando ser esta mais uma reforma de ensino sem uma política eficaz de implantação. Tomando por base os três princípios básicos das DCNEM: a estética da sensibilidade, a política da igualdade e a ética da identidade, nos quais a interdisciplinaridade se coloca como estratégia fundamental, ela questiona se os profissionais da educação estão preparados para implementá-la. Entrando no seu próprio campo de atuação - linguagens e códigos -, a autora aborda a questão dos meios de comunicação em sala de aula, discutindo como é possível integrá-los ao espaço educativo sem que ocupem/substituam o espaço que é próprio da escola. Para essa discussão, utiliza o texto publicitário, demonstrando como a análise e desconstrução de sua linguagem são importantes tanto para a implementação dos temas do currículo quanto para a formação crítica.

Palavras-chave: LDB, DCNEM, interdisciplinaridade, competências e habilidades, linguagens e códigos, gramática textual, publicidade/propaganda satisfeito, gera frustração. O cotidiano se estampa e vai constituindo as subjetividades.

Cada um é dono do seu olhar e o orienta conforme o eu. As forças sociais são intensas, opressoras, mas reinventar o cotidiano é sempre possível: são as artes do fazer ${ }^{17}$. É rotina, mas é também fonte de sabedoria, o solo onde pode germinar a semente da vida, recriada.

Portanto é imperativo repensar o processo de ensino-aprendizagem nas diferentes áreas e, mais especificamente, na de Linguagens, Códigos e suas Tecnologias, que inclui a língua materna, por ser a base para as demais áreas/disciplinas.

Para entender essa concepção de mundo (ainda que não se aceite), a publicidade é um caminho. A interação currículo escolar e meios de comunicação e linguagem verbal, outro.

Abstract: Based on the analysis of the new LDB (Base and Directives Law) and of the DCNEM, the author questions the autonomy proposed by the legislation, considering this to be yet another education reform that does not have an efficacious implementation policy. Considering the three basic DCNEM principles: sensibility aesthetics, equality policy and identity ethics, in which the interdisciplinary mode is placed as a fundamental strategy, she questions whether or not educational professionals are ready to implement it. Entering her own field of performance - languages and codes -, the author covers the means of communication in the classroom matter, discussing how it is possible to integrate them in the educational space without the space that belongs to school itself being occupied/substituted. For this discussion, she uses publicity texts, demonstrating how language analysis and deconstruction are important, both to implement the curriculum themes and also for critical forming.

Key words: LDB, DCNEM , inter-disciplinary, competence and abilities, languages and codes, textual grammar, publicity/propaganda 